\title{
Claw tuft setae of tarantulas (Araneae, Mygalomorphae, Theraphosidae) and the production of fibrous materials. Do tarantulas eject silk from their feet?
}

\author{
Jaromír Hajer and Dana Řeháková \\ Department of Biology, J. E. Purkinje University, \\ České mládeže 8, 40096 Ústí nad Labem, Czech Republic \\ Address correspondence and requests for materials to Jaromír Hajer, Jaromir.Hajer@ujep.cz
}

\begin{abstract}
The study focused on the specialised tarsal setae of tarantulas Avicularia metallica and Heteroscodra maculata, and the fibrous and non-fibrous material produced by them. When irritated spiders moved along smooth, perpendicularlyoriented glass walls not covered in silk, the claw tuft setae, located at the tips of the tarsal segments, left behind footprints containing two types of fibrous material. Using electron scanning microscopy, it was discovered that these represent fragments of parallelly oriented bundles of hollow fibres forming the shafts of the setae and their lateral branches (1), as well as clusters of contracted nanofibrils which aggregated at the ends of these fibres (2). During climbing, this fibrous material was detected both on the substratum on which the spiders were moving, and also on their claw tuft setae. The climbing activity of irritated tarantulas is also associated with the secretion of a fluid which dries on contact with air. This secretion acts as an adhesive and facilitates the movement of tarantulas on smooth surfaces, but while doing so it also glues together the distal, lamellar parts of the groups of setae which are in contact with the substratum during climbing. There are no such claw tuft setae morphological changes observed in undisturbed tarantulas, moving freely around their tube-like shelters and on the surfaces of objects covered with silk which they have produced. The sources of the air-drying secretion are probably the tubular fibres forming the shafts of pretarsal setae. The bundles of hollow fibres are an example of a system that produces secretions via a surficial pathway. The spinnerets and silkproducing glands associated with them, located in the opisthosoma, represent a system that produces silk via a systemic pathway. However, the results of observational studies have not confirmed the ability of tarantulas' feet to produce silk fibres of the same, or at least similar ultrastructure to that of the silk fibres produced by the activity of spinnerets and spinneret-associated silk glands.
\end{abstract}

Keywords: spiders, adhesive setae, claw tufts, tarsal secretions, tarantula silk.

\section{Introduction}

Department of Vertebrate Zoology, Faculty

of Biology, Saint Petersburg State University,

Saint Petersburg, Russia

Received: June 25, 2019;

Revised: August 26, 2019;

Accepted: August 27, 2019;

Copyright: @ 2019 Hajer and Řeháková. This is an open-access article distributed under the terms of the License Agreement with Saint Petersburg State University, which permits to the authors unrestricted distribution, and self-archiving free of charge.

Funding: No funding information provided Competing interests: The authors have declared that no competing interests exist.

The ability to produce silk has evolved multiple times in invertebrates (see Craig, 1997; Sutherland et al., 2010; Neretin, 2016), and silk-secreting organs have evolved via two different pathways: systemic (1), in spiders represented by silken glands placed in the opisthosoma, and surficial (2), represented by cuticular secretion (Craig, 1997). The silk-spinning apparatus of spiders consists of spinnerets and silk-producing glands. In spiders, these glands originate from ectodermal invaginations on the embryonic spinneret limb buds, in relation to the morphogenesis of these buds (Hilbrant and Damen, 2015).

Spinnerets are equipped with spigots (nozzles), i.e., external outlets of glands. Spigots are considered to represent modified setae (Bond, 1994; Eberhard, 2010; Foelix, 2011). As well as the spinning glands themselves, the spigots are classified 
into several different types (Eberhard, 2010; Foelix, 2011). Aside from the spinnerets, the adult males of some species are also equipped with epiandrous (or epigaster) glands, which are associated with genital furrow (Shultz, 1987). The spigots associated with these glands resemble the spigots of spinnerets (Marples, 1967; Ferretti et al., 2017), although it is not entirely certain whether the secretion produced by these can be truly considered as silk (Garb, 2013). Epiandrous glands, together with the aciniform silk-producing glands associated with spinnerets, provide material for the construction of special sperm webs, which are created by mature males in order to transfer sperm from the gonopore to the palpal bulbus and to encourage sperm droplet induction (Lopez and Emerit, 1988). Adult male tarantulas (Theraphosidae) are also equipped with these glands, similarly to the males of other families of the infraorder of Mygalomorphae (Feretti et al., 2017).

Recently a number of studies have been published in which the authors suggest that silk-producing organs are not only the spinnerets and spinneret-associated glands, but also the feet of spiders. Gorb et al. (2006) observed the "footprints" made up of a fibrous secretion left by the feet of tarantula Aphonopelma seemani (F.O.Pickard-Cambridge, 1897) while moving on a vertically-oriented glass wall. In the end, these authors concluded that this represents an adaptative mechanism designed to prevent the spider's legs from slipping when moving on smooth surfaces. Similar conclusions were also reached by Rind, Birkett, Duncan, and Ranken (2011), who studied the feet of other theraphosid species. These authors also described the "ribbed hairs", i.e., setae, which according to them bear a strong resemblance to the spigots through which silk is emitted onto the surface of spinnerets. However, these findings were called into question by behavioural experiments (Perez-Miles, Panzera, Ortiz-Villatoro, and Perdomo, 2009) as well as morphological and histological studies of the feet of tarantulas (Foelix, Rast, and Peattie, 2012; Foelix, Erb, and Rast, 2013).

Perez-Miles, Panzera, Ortiz-Villatoro, and Perdomo (2009) consider the "tarsal silk" to be a result of contamination of the feet with the silk produced by spinnerets and spinneret-associated silk glands. Foelix, Rast, and Peattie (2012) and Foelix, Erb, and Rast (2013) found that the setae which Rind, Birkett, Duncan, and Ranken (2011) thought to be spigots, were actually more likely chemoreceptors. Histological studies have not yet proven the presence of silk glands in the tarsal segments, leading to the conclusion that "the alleged presence of silk spigots on the tarantula's legs is refuted" (Foelix, Erb, and Rast, 2013).

The Theraphosidae family consists of hairy and often large spiders, which are capable of climbing on smooth surfaces, including perpendicular glass walls. This is enabled by their adhesive foot pads (scopulae) which can be found on both the metatarsal and tarsal leg segments in theraphosids (Foelix and Chu-Wang, 1975). An impor- tant structure of tarantula feet, similarly to many other wandering spiders (Wolff and Gorb, 2012), are claw tufts (also called pretarsal scopulae), which are defined as dense arrays of adhesive setae, located at the tip of the tarsus ventrally of the paired claws (Niederegger, 2013). The movement of the pretarsus and other structures in the spider foot is provided, apart from the muscles, by the arthrodial membrane and haemolymph pressure (Dunlop, 1995; Kropf, 2013; Labarque et al., 2017).

The setae of scopulae and claw tufts are covered on their distal, lamellar part by microtrichii (setules) with spatula-shaped endings, which increase adhesion (Wolff, Nentwig, and Gorb, 2013; Perez-Miles, Perafan, and Santamaria, 2015). Spatulae are plate-like termini of the setulae, providing the contact surface for van der Waals attraction in adhesion. Setose (or hairy attachment) systems structured in this way show a higher reliability of contacts on various surface profiles (Arzt, Gorb, and Spolenak, 2003; Niewiarowski, Stark, and Dhinojwala, 2016).

The scopulae of spiders are usually reported as dry adhesive devices, although Peattie, Dirks, Henriques, and Federle (2011) found the presence of thin liquid films in the adhesive contact zones of tarantulas Grammostola rosea (and several other arachnids). The tarsal fluid probably improves adhesion of feet to the substratum (Peattie, Dirks, Henriques, and Federle, 2011). Several authors (Dunlop, 1995; Foelix, 2011; Foelix, Rast, and Peattie, 2012; Niederegger, 2013) proposed that when the tarantulas walk on vertical glass they only use claw tufts for adhesion, while the tarsal and metatarsal scopulae are used for hunting. Perez-Miles, Perafan, and Santamaria (2015) reported that tarsal scopulae could also participate in locomotory adhesion. Foelix, Rast, and Peattie (2012) studied the adhesion of some tarantula species on glass and found that arboreal species show better adhesion than terrestrial ones.

The aims of this research, the results of which are presented in this paper, were:

(1) To examine and describe the changes in the microand ultrastructure of claw tuft setae, which occur during the fast climbing of irritated and stressed tarantulas on smooth-surfaced objects, including perpendicularly-oriented glass walls.

(2) To examine the micro- and ultrastructure of the fibrous and non-fibrous material which appears on the tarsal segments (especially on the setae of claw tufts) and on the glass walls of the spiders' breeding containers during the movement of tarantulas on smooth and non-silk-covered surfaces.

(3) To clarify the origin and source of the studied fibrous material and to compare its ultrastructure with the ultrastructure of silk fibres produced by the spinnerets and the spinning glands located in the opisthosoma associated with them. 
When determining these aims the authors of this article considered the hypothesis that spiders do leave silken fibre-like "footprints" when moving on smooth surfaces to be sufficiently proven (Gorb et al., 2006; Rind, Birkett, Duncan, and Ranken, 2011). What may however raise doubt is the opinion that this residue is made up of silk, the chemical composition and ultrastructure of which after solidification is identical to the silk produced by spinnerets. The origin of this secretion has not yet been clarified; that is, there are no known glands or cells by which this secretion could be produced. The mechanism through which this secretion could be emitted onto the surface of the distal segments of tarantula feet is also not currently clear. The authors worked on the assumption that if the fibres observed on the distal segments of the legs really are in fact a contamination by the true silk that is, silk produced by spinnerets (Perez-Miles, Panzera, Ortiz-Villatoro, and Perdomo, 2009) - then they should possess the same ultrastructure as the fibres the tarantulas use to build their retreats or make their egg sacs.

\section{Materials and Methods}

\section{MATERIALS AND METHODS OF KEEPING SPIDERS IN LABORATORY CONDITIONS}

The studied spiders were the neotropical theraphosid species Avicularia metallica Ausserer, 1875 (Fig. 1A, C, D) and Old World species Heteroscodra maculata Pocock, 1899 (Fig. 1B). All specimens of both the studied species were obtained from tarantula breeders in the Czech Republic.

Avicularia metallica is an arboreal and rainforest species found in silken tube retreats in the crevices of trees, in holes under bark or under epiphytes and on rainforest vegetation (Jocqué and Dippenaar-Schoeman, 2006). This particular species, called metallic "whitetoe" or metallic "pinktoe" (with a diagonal leg span of approximately $13-15$ centimetres), is found mainly in Columbia and Suriname (World Spider Catalog, 2019). The studied cohort was made up of two adult females, two adult males, and four nymphs of an undetermined instar, of the body size (prosoma + opisthosoma) of 15-18 mm.

Heteroscodra maculata ("ornamental baboon"), with a diagonal leg span of approximately $11-12 \mathrm{~cm}$, is also an arboreal species (Charpentier, 1992). These spiders are widespread in West and Central Africa (Charpentier, 1992; World Spider Catalog, 2019). Charpentier (1992) considered short palm trees to be the preferred habitat of these spiders. The studied material consisted of three adult females and six nymphs of various ages, with a body size of $15-35 \mathrm{~mm}$. The exuviae of these spiders were also studied.

The research work and its conclusions presented in this study build on the results of our previous study of the silk and silk-producing organs of Avicularia metallica (Hajer, Karschová and Řeháková, 2016). All the spiders were individually housed and fed with insects (mainly crickets and grasshoppers), the size of which corresponded to the size of the studied tarantulas (for details see Hajer, Karschová and Řeháková, 2016). Chloroform was used in order to kill the individual spiders selected for further evaluation with the electron scanning microscopy.

A Dino-Lite Digital Microscope was used to observe the spinning activity of spiders and their behaviour (Figs. 1A-D, 2A-B). All experiments involving tarantulas were conducted in the Biology Department at the University J.E.Purkinje in Ústí nad Labem, Czech Republic.

\section{METHODS OF OBTAINING THE FIBROUS AND \\ NON-FIBROUS MATERIAL PRODUCED BY \\ THE FEET OF IRRITATED TARANTULAS}

In order to clarify the morphological changes of claw tufts which occur as a result of the tarantula's movement on smooth surfaces, and also in order to obtain the material coming from their "footprints", the adult male specimens were temporarily placed into glass containers measuring $20 \times 25 \times 35 \mathrm{~cm}$, the walls of which were not permanently glued together but instead placed into a metal construction from which they could be removed at any time.

The smaller nymphs were temporarily placed into glass cubic vessels with an edge length of $8 \mathrm{~cm}$. The walls of these vessels were held together by magnets which were glued to their corners. Due to the small size of these walls it was possible to scan the footprints in situ, directly on their surface. There were no other objects inside the containers, into which the spiders were regularly placed for the duration of 15-20 minutes. In order to irritate the tarantulas, the glass walls of the containers were tapped on, following which the tarantulas could move only on the glass walls. The places where the feet of resting spiders touched the glass walls were marked by a felt-tip pen from the outside of the container (Fig. 1A). In the case of the adult specimens, kept in the larger containers, the fibrous material intended for SEM study was scraped off the glass wall of the container with the knife removed from the microtome. This material was then compared with the fibres transferred to the claw tuft setae through climbing.

\section{SCANNING ELECTRON MICROSCOPY IMAGING EQUIPMENT}

For the imaging of spinnerets, spigots and the ultrastructure of fibres, a TESCAN SEM Microscope was used (Figs. 3A-D, 4A-B, 6A-C, 7A-D), as well as the UHR-SEM Zeiss Ultra Plus Microscope (Figs. 2C-D, $5 \mathrm{~A}-\mathrm{C}, 8 \mathrm{~A}-\mathrm{D})$, operated at low acceleration voltage of $1 \mathrm{kV}$. For the SEM studies, the spiders were killed by chloroform, dehydrated in ethanol, and processed via critical point drying using carbon dioxide. Prior to ob- 

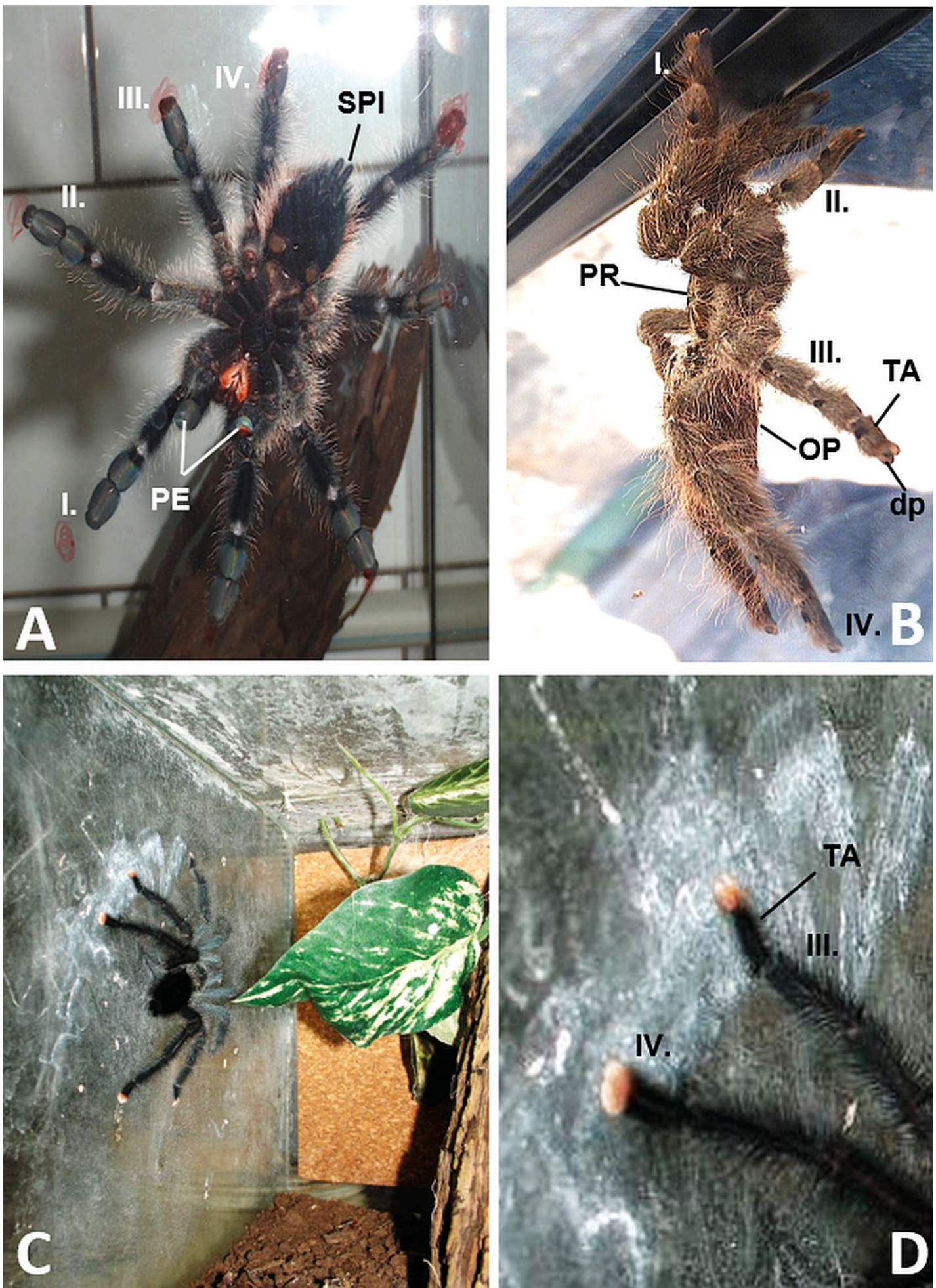

Fig. 1A-D. Studied tarantulas inside the glass containers. A - nymph (juvenile male) of Avicularia metallica (body size of $5.5 \mathrm{~cm}$ ) resting on the glass wall - ventral view. The places where scopular setae of the tarsal segments touched the glass wall were marked with a felt-tip pen. B - Lateral view of the adult female Heteroscodra maculata (body size of $6.5 \mathrm{~cm}$ ) climbing on the glass wall. C, D - adult male Avicularia metallica resting on the glass wall of the insectary after charging his palpal bulbs with sperm. Overview of the sitting spider (C) and detail of the third (III.) and fourth (IV.) pair of legs (D). In this case, the male was moving on a glass wall covered with silk. Under the tarsal segments of the legs on the left side of the body there are white, silk spots visible. they are not present on the right side. The "footprints" in this case were the result of the spider's effort to maintain contact with the substratum by rubbing and applying pressure on the feet of the left side of the body, so that a possible turnover of the body around the anterior-posterior axis resulting in a free fall onto the bottom of the container is prevented. The quality of the image is partly influenced by the high moisture inside the insectarium and the drops of condensed water on its glass walls.

PE - pedipalps, PR - prosoma, OP — opisthosoma, SPI — spinnerets, TA - tarsus and its distal part (dp) called pretarsus, I. - IV. - first to fourth pairs of legs. 

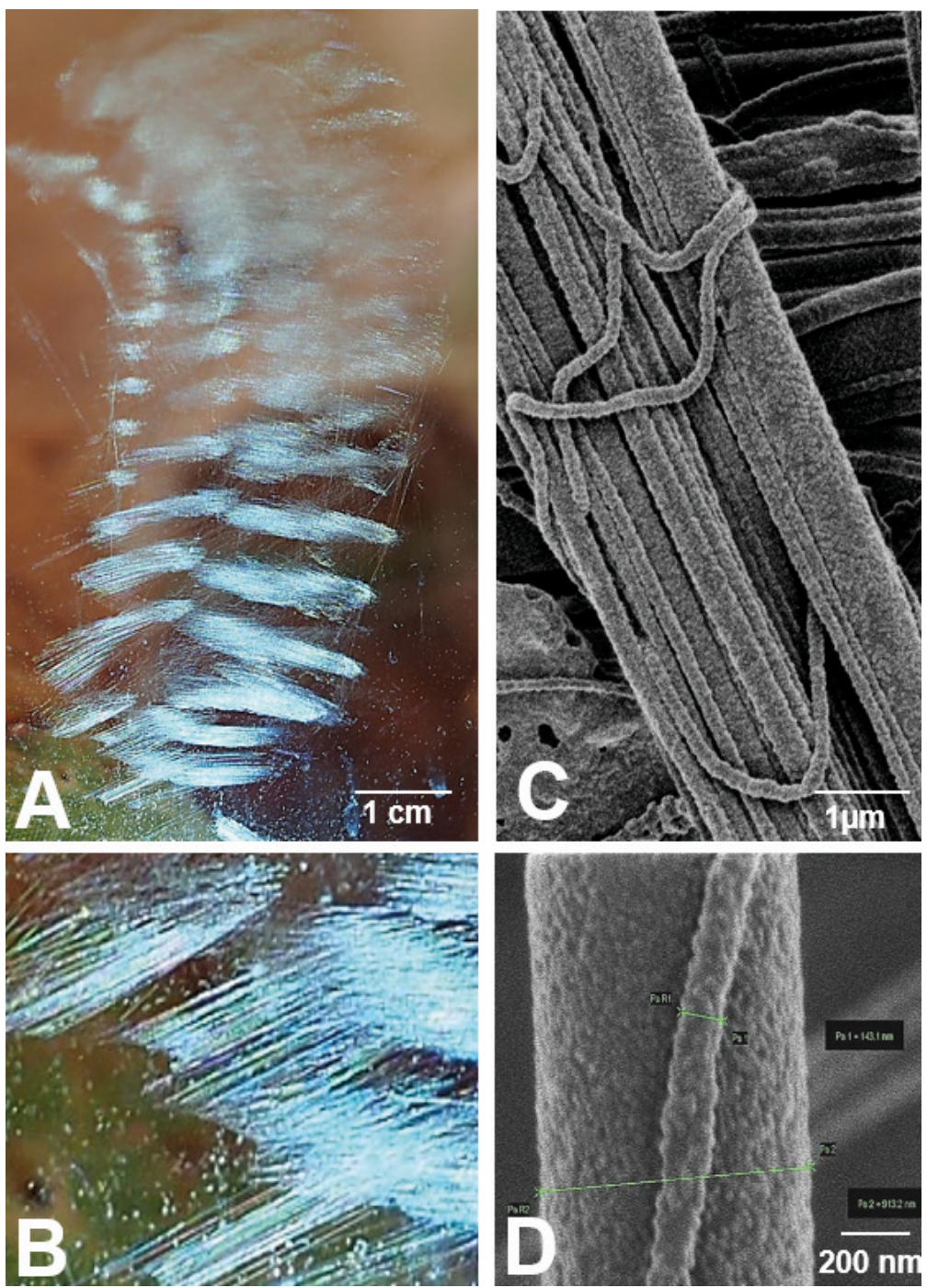

Fig. 2A-D. Silk traces created by a non-irritated female Avicularia metallica, left behind when climbing a glass wall. A - an overview of the series of silk prints left on the glass by the female and a detail of their microstructure (B).

Every print has a distinctly fibrous structure and is created by the movement of a single spinneret, equipped with many spigots, on the surface of the glass. C - SEM micrograph of a bundle of the nanofibrils. D - a detailed view of the nanofibrils of varied thickness.

servation, the samples were coated with a 1-nm-thick layer of platinum. A Quorum Q R150ES sputter coater was used for the coating. Measurement/image analysis was carried out using SmartSEM software.

\section{Results}

\section{THE MOVEMENT OF TARANTULAS AND FIBROUS FOOTPRINTS}

The movement of tarantulas, during which their feet leave behind footprints containing fibrous or non-fibrous material, is influenced by the substratum type, its orientation and position (from the horizontal to the vertical), as well as the microstructure of the surface. Also, the speed and reason for why the spiders are moving on a particular type of substratum are important factors influencing the finding of footprints and their composition.

Following the construction of a silk, tube-like shelter which they can then inhabit for several months or years, tarantulas begin to gradually cover the surface of objects in their direct vicinity with a thin layer of silk (Fig. 1C-D). This activity is carried out predominantly at night, when these spiders can move freely, undisturbed around their shelters. In this case, the spinning activity is associated with slow movement on the substratum, which the spiders touch simultaneously with their feet as well as the two pairs of spinnerets. The silk fibres visible on the glass (Fig. 2A-B) are therefore the product of the 

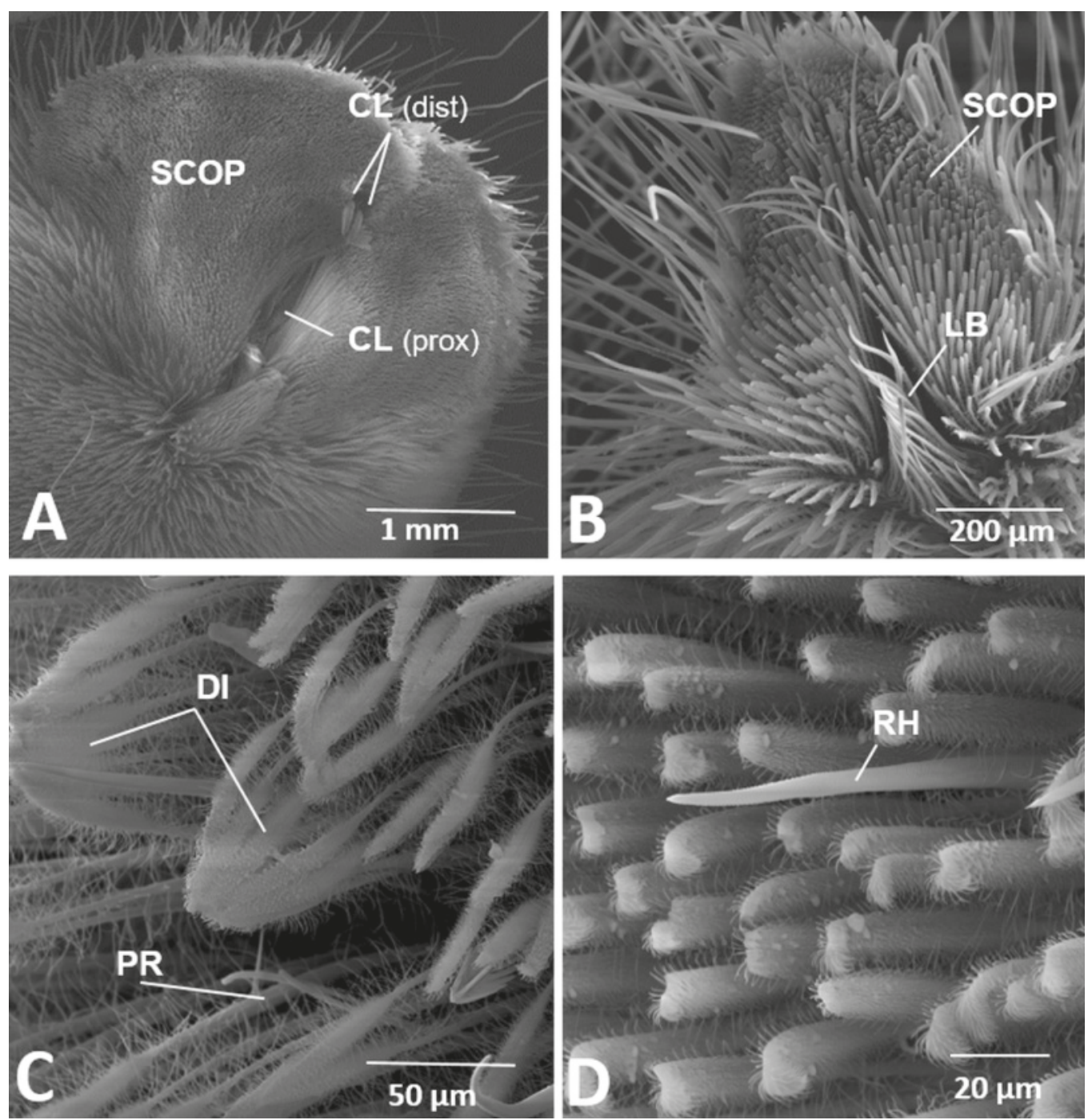

Fig. 3A-D. Overall views of the tarsal scopula and the microstructure of the scopular setae of the fourth pair of the legs of non-irritated tarantulas Avicularia metallica $(A, C)$ and Heteroscodra maculata $(B, D)$. Due to low hemolymph pressure, claws and claw tufts are partly (A) or completely (B) retracted and therefore difficult to observe. $\mathrm{CL}$ (dist) - distal parts of the claws, $\mathrm{CL}$ (prox) - proximal part of the claws, connected with the sclerotized basal plate, DI, PR - distal and proximal part of scopular setae, LB - longitudinal band of setae, dividing the scopula into two parts. $\mathrm{RH}$ - ribbed hair, SCOP — scopula.

spinning activity of spinnerets. When the spinnerets rub against the ground and when the terminal parts of spigots come into contact with the substratum, each spigot extrudes a separate nanofibril, i.e. a separate "silk trail". It is only after the spinnerets are lifted and put into motion above the substratum that the nanofibrils are joined laterally (Fig. 2C).

Nanoglobules (spherical subunits) are the basic microstructural blocks in the silk materials studied (Fig. 2C-D) (see also Hajer et al., 2016). After several days the glass perpendicular walls of the large breeding containers, as well as the objects placed inside them, were covered with a fine layer of silk. In that case there is a silken coating found between the surface of the object on which the spider moves and the distal ends of the tarsal segments equipped with claw tuft setae (Fig. 1C-D).
As a result, the tarantulas touch the same fibrous material when they attack prey, move around their shelter, during resting or basking as they are moving inside their tube-like shelter.

However, quite a different situation arises when these spiders are forced by external circumstances to move on the surface of objects which are not covered in silk. As the authors of this study observed, irritated tarantulas running away from danger on a smooth glass wall always had their spinnerets firmly pressed to the cuticle of the opisthosoma in such a way that the fairly long, distal segments of their three-segmental posterior lateral spinnerets were touching their dorsum. During this fairly fast movement, which essentially represents a flight response to danger, the spinnerets were never in contact with the glass surface and their spigots never 

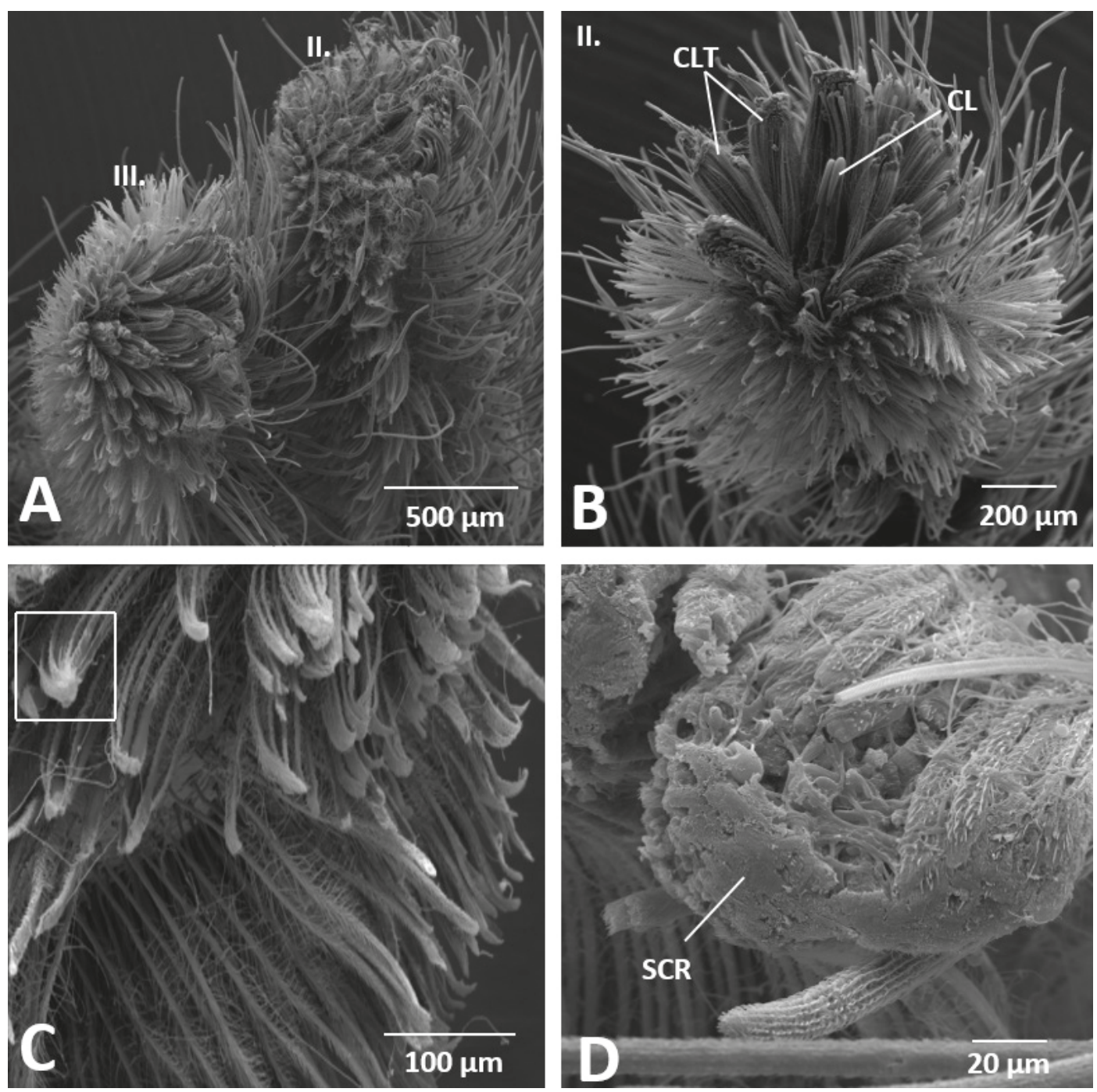

Fig. 4A-B. SEM micrographs of distal tips of claw tufts setae. A - lamellae covered with microtrichii and ribbed hairs. $B-$ detail of the ribbed hair $(\mathrm{RH})$.

emitted silk. Therefore, in these fairly large, adult-stage spiders, the only protection from falling is provided by the adhesive setae on their legs, including the claw tufts at the tip of the tarsus.

\section{TARSAL SCOPULAE AND CLAW TUFT SETAE OF NONSTRESSED SPIDERS (BEFORE CLIMBING ON NON-SILK-COVERED VERTICAL GLASS PLATES)}

The distal parts of the tarsal segments of all four pairs of legs of Avicularia metallica and Heteroscodra maculata are, similarly to most other tarantula species, equipped with scopulae, i.e., adhesive pads (Figs. 3A-B). The scopulae of both of the species studied are divided into parts by longitudinal bands of non-adhesive setae (Fig. 3B).

The adhesive setae, including the ones found in the direct vicinity of the pair of claws (i.e., claw tuft setae) are made up of a proximal part, called shaft and distal, and an apically broad part, called lamella (Fig. 3C-D). The mi- crostructure and ultrastructure of both of these parts differ significantly from each other, as their role in securing the safe movement of spiders on various surfaces is undoubtedly different as well. In the studied specimens the claws and claw tuft setae located directly adjacent to them were either partially (Fig. 3A) or completely (Fig. 3B) retracted. Amongst the claw tuft setae so-called "ribbed hairs", the length of which exceeds the neighbouring adhesive setae, were also observed (Figs. 3D, 4A-B). At the ends of these ribbed hairs it was possible to detect a small amount of solid amorphous mass (Fig. 4A-B). The distal, lamellate parts of claw tuft setae were covered by numerous microtrichii (Figs. 3C-D, 4A).

The shafts of adhesive setae are always made up of bundles of hollow, tubular and parallelly oriented fibres (Fig. 5A-C). Some of these fibres branch off from the main stem (either in the form of smaller bundles or individual fibres) (Fig. 5B-C) and form the lateral branches. This branching may be observed along the entire length 

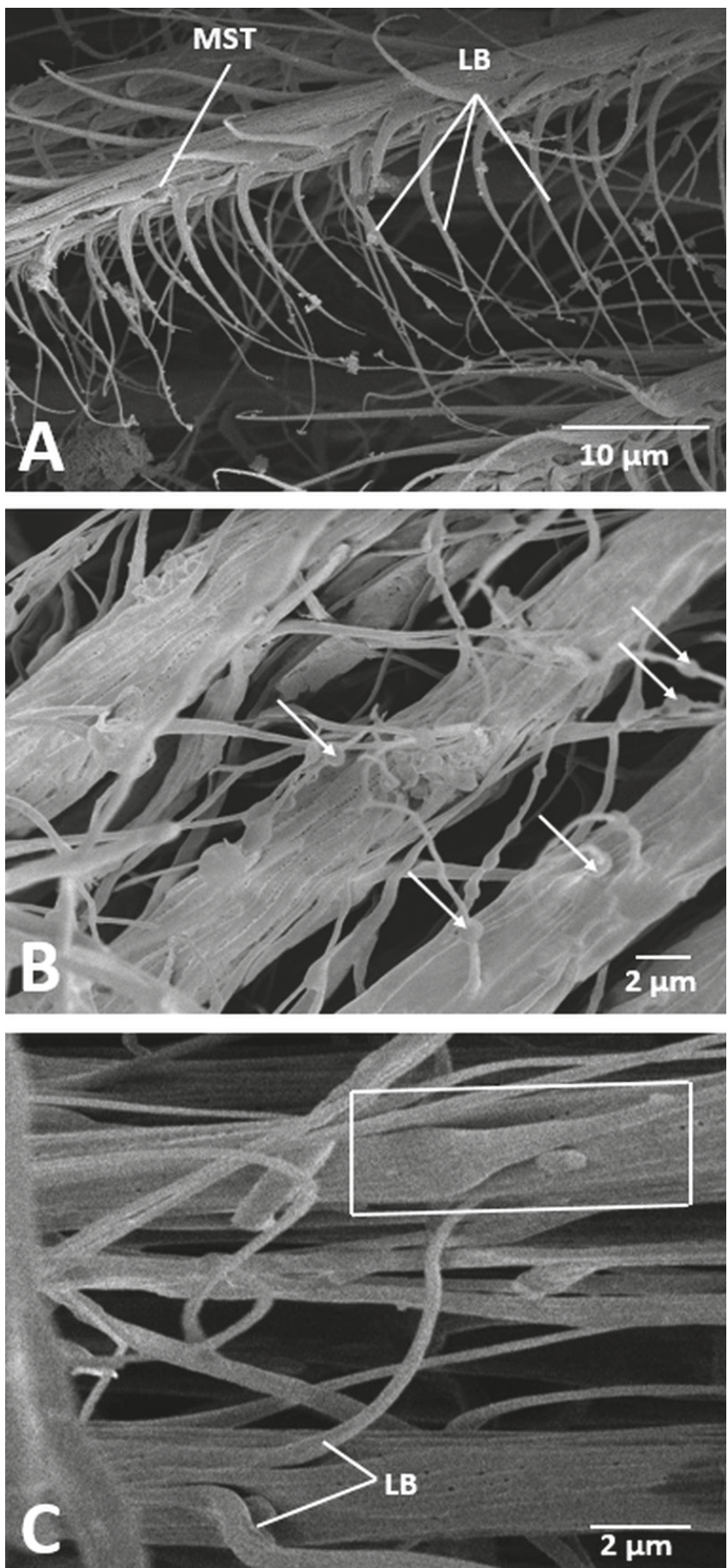

Fig. 5A-C. SEM micrographs of the branched shafts of claw tuft setae. A - main stem (MST), made up of bundles of hollow fibres and lateral branches (LB), which represent bundles of tubes branching off of the main stem. PF - parallel fibres oriented longitudinally to the long axis of the stem. The arrows point to the droplets of solidified fluid.

of the shaft, however the number, as well as the total length of these fibres, increases in the direction towards the distal end (Fig. 6A-C). The tubular fibres comprising the above-mentioned bundles are not all of the same length. The ends of these branches consist of only one fibre, the length of which sometimes exceeds the length
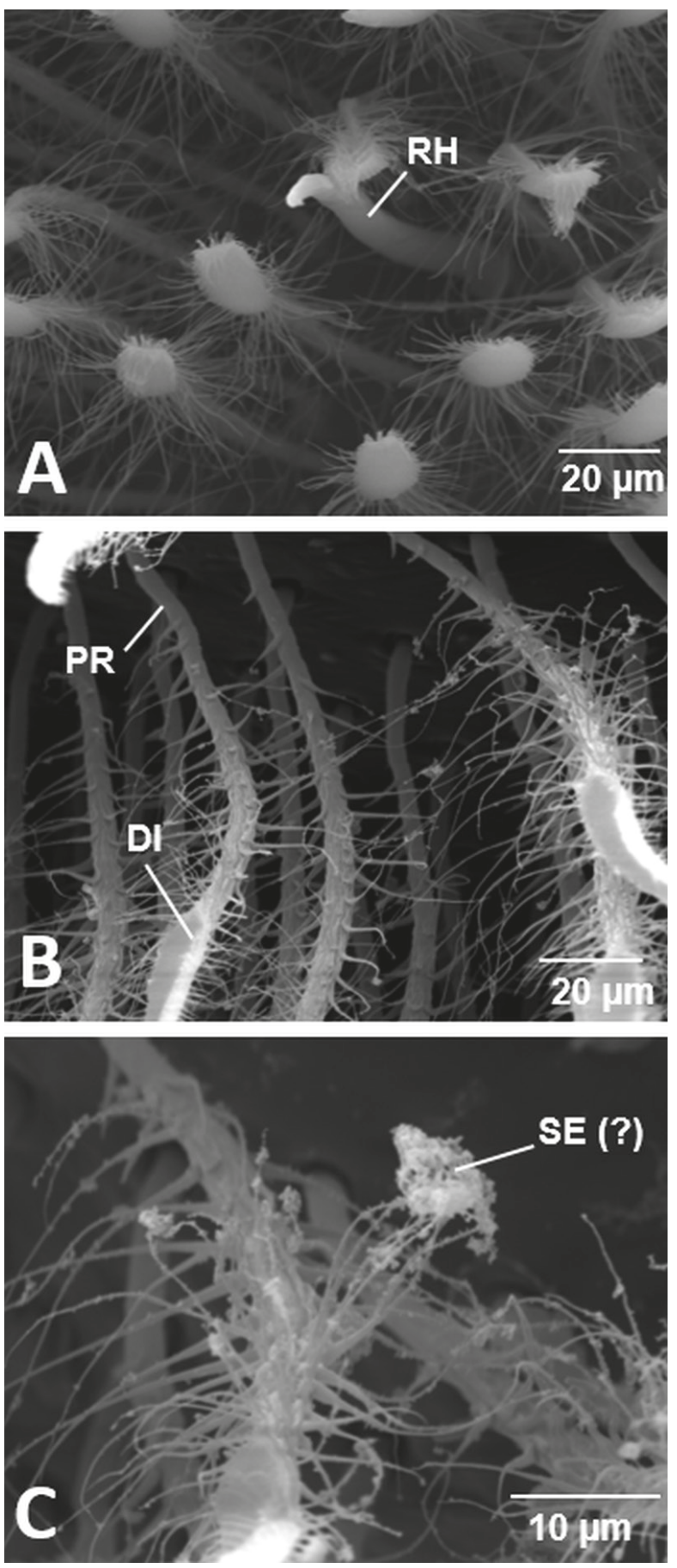

Fig. 6A-C. The microstructure of the branched distal parts of the adhesive setae of pretarsal scopula of the Avicularia metallica (A) and Heteroscodra maculata $(B, C)$. The lateral branches in the vicinity of the terminal lamellae, forming the distal ends of the adhesive setae, are the lengthiest of the branches. DI - distal, PR - proximal part of setae, $\mathrm{RH}$ - ribbed hair, SE (?) - probably scleroprotein secretion in the form of a contracted nanofibril.

of the entire setae (Fig. 6B). At the very thin ends of these tubes, especially the ones located in the vicinity of the lamellae, there are tufts of contracted nanofibrils (Fig. 6C). These probably represent the hardened (possibly scleroprotein in nature) secretion produced by the tubular fibres (see also Fig. 8C) which make up the stalk. 

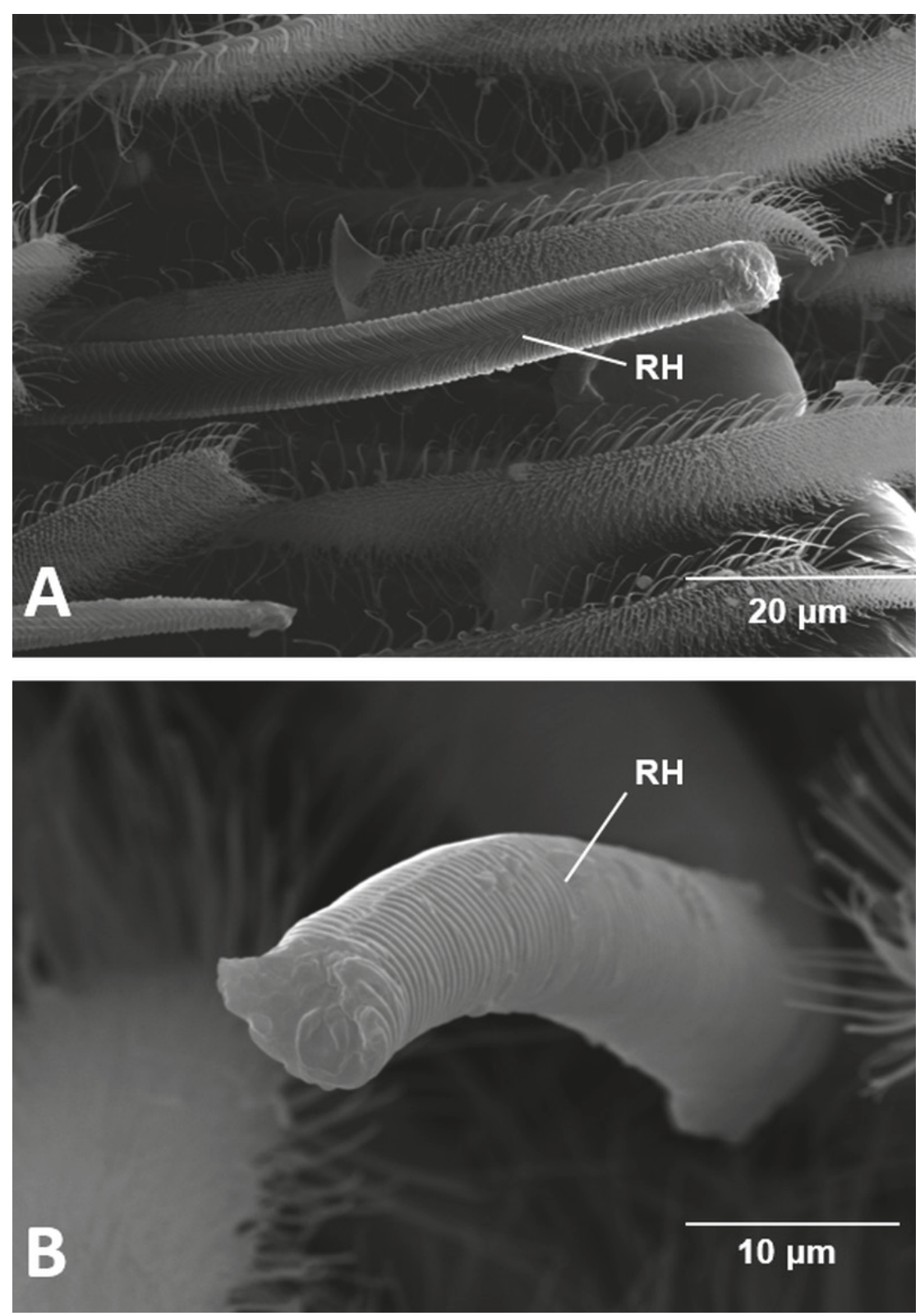

Fig. 7A-D. Claw tuft setae at the tarsal tips of the legs of a female Avicularia metallica, after intensive climbing on the glass wall of the container. A - tarsal segments of the second (II.) and third pair (III.) of legs, with fibres demonstrated at the ends of the glued-together claw tuft setae. B - claw tufts of the fourth pair of the legs. C - the boundary between the bundles of glued-together claw tuft setae and setae which remained free. D - detail of the bundle of glued-together setae (framed in Fig. 7C). Distal parts of the setae are covered with non-fibrous secretion, which almost completely obscures the original surface structure. $\mathrm{CL}$ - claws, CLT - claw tufts, SCR - secretion produced by adhesive setae, located at the tip of the tarsus.

THE MORPHOLOGICAL CHANGES OF CLAW TUFT SETAE CAUSED BY THE CLIMBING OF IRRITATED AND STRESSED TARANTULAS, FLEEING FROM DANGER, ON VERTICAL GLASS PLATES

Under these conditions the originally distinct and separated claw tuft setae, which while climbing were in contact with the glass, non-silk-covered surface, now formed groups (Fig. 7A-D) made up of several setae, the distal lamellar ends of which were partly glued together with a hardened non-fibrous secretion (Fig. 7C-D). This secretion probably acts as an adhesive during motion on a smooth substratum. The origin and significance of this secretion has not yet been fully elucidated (see Discussion). The presence of this amorphous material on the glued-together ends of the setae distinctly marks the adhesive setae which were in contact with the glass surface while climbing (Fig. 7C). The accumulated hardened secretion completely obscures the original microtrichial ultrastructure of the distal parts of the setae (Fig. 7D). 

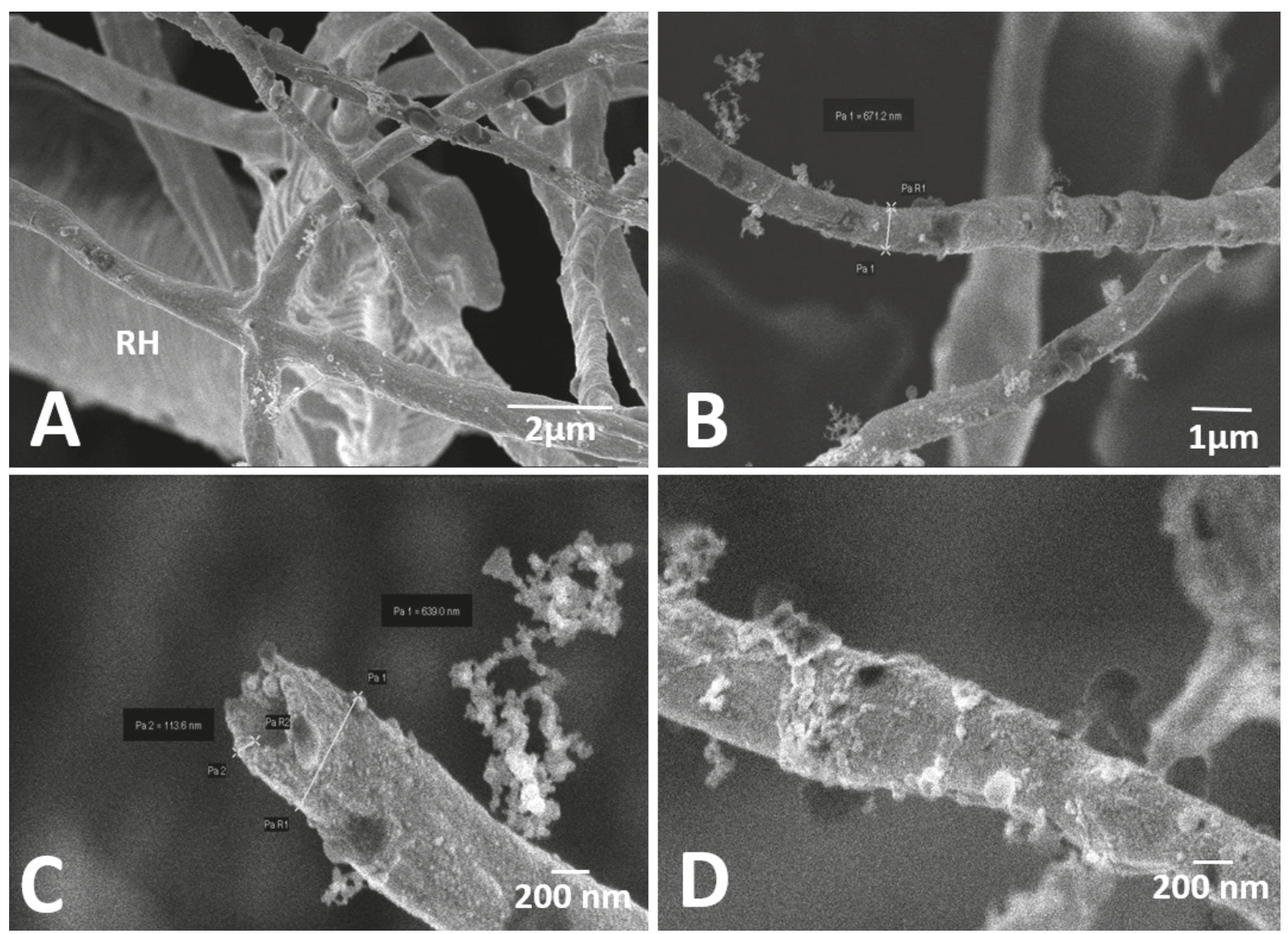

Figs. 8A-D. Ultrastructure of the fibrous material produced by an irritated tarantula Avicularia metallica during climbing on a smooth, glass surface. A - fragments of tubular fibres, that is, fibres which comprise the shafts of claw tuft setae, depicted at the tip of the tarsus. There is a ribbed hair $(\mathrm{RH})$ visible in the background. $\mathrm{B}-$ fibrous material left on the glass. $\mathrm{C}-\mathrm{broken}$ off ending of one of the hollow fibres, and a cluster of contracted nanofibrils. D - detail of the surface of one of these fibres.

\section{FIBROUS AND NON-FIBROUS MATERIAL PRODUCED BY THE FEET AND ITS PROBABLE ORIGIN}

The fibrous material visible on the bundles of gluedtogether claw tuft setae of all the four pairs of tarantulas' legs is fundamentally identical to the material left by their feet while climbing on a glass wall (Fig. 8A-D). In both cases the material is made up of fragments of hollow nanofibrils which form the shafts, their lateral branches (i) and the tufts of contracted nanofibrils (ii) (Fig. 8C) which were originally attached to the terminal fibres of these branches. The third type of material observed on the distal parts of setae is a fluid secretion which, after solidification, functions as glue and binds together the ends of the setae, effectively changing their appearance and the ultrastructure of their surface, as it obscures the microtrichia and therefore obscures the contact points between the tarantulas and the substratum as well. The claw tuft fibres (Fig. 8C-D) and silk fibres arising as a result of the activity of the spinnerets and spinneret-associated spinning glands (Fig. 2C-D) show different ultrastructure.

\section{Discussion}

The movement of tarantulas on the surface of objects is, as well as the way of life of all spiders in general, influenced by their ability to produce silk. There is no doubt that the evolution of the spinning apparatus of spiders is associated with the evolution of their limbs. During evolution, spiders developed a number of different appendage types "with radically different adult morphologies" (Pechmann, Khadjeh, Sprenger, and Prpic, 2010). Spinnerets are highly modified opisthosomal appendages (Kautzch, 1910; Yoshicura, 1955; Pechmann, Khadjeh, Sprenger, and Prpic, 2010), that arise embryologically from the same longitudinal series of limb buds (Dawydoff, 1949) which give rise to the prosomal appendages - i.e., chelicerae, pedipalps and legs (Dawydoff, 1949; Whitehead and Rempel, 1959). Seyfarth (1985) reported that the spinnerets of mygalomorphs can be seen to move simultaneously with the walking motion of the legs during locomotion. Shultz (1987) suggested that these appendages share a serially arranged motor control mechanism as well as similar 
developmental origins. While spinnerets are found in all spider species, albeit in different numbers, adhesive setae can be found in only some of the species.

The highest number of spinnerets (i.e., four pairs) was recorded only in the spiders of the species Liphistius Schiödte, 1849 (family Liphistiidae), belonging to the infraorder Mesothelae. These spiders possess two pairs (anterior lateral - ALS, and anterior median - AMS) of spinnerets on the fourth opisthosomal segment, and two pairs (posterior lateral - PLS, and posterior median - PMS) on the fifth segment (Yoshicura, 1955; Haupt and Kovoor, 1993). These ground-dwelling spiders, found in East Asia and Southeast Asia, are known for building trapdoor burrows used as shelters and for prey capture (Haupt, 2003). In order to attach their fibres to the ground, Mesothelae, unlike spiders of the infraorder Araneomorphs (see below), do not use attachment discs but their silk is "attached immediately after leaving the spigots" (Haupt and Kovoor, 1996).

The presence of setae similar to scopular hairs was reported in adult males of the genus Liphistius (Foelix, Erb, and Michalik, 2010). However, their presumed function is the perception of female pheromones (Foelix, Erb, and Michalik, 2010). So far, the ability to produce fibrous (or non-fibrous) secretion drying in contact with air by their feet has not been confirmed for any of the Mesothelae infraorder species.

Apart from the Mesothelae, four pairs of spinnerets are never formed in any other species, since the anterior median pair is not developed in these. Most of the 48,231 spider species discovered so far (belonging to 4,140 genera and 119 families) (World Spider Catalog, 2019), belong to the infraorder Araneomorphae (total of 44,656 species). These spiders are equipped with three pairs of spinnerets (ALS + PMS + PLS) and the ability of ALS to produce draglines, fibres which exhibit a unique combination of strength and toughness (Tirell, 1996) and which, given their essential meaning to the life of araneomorphs, are also called lifelines (Osaki, 1996). Anchored to the substratum by attachment discs, the lifeline allows the spider to return safely to the starting point after a thrust at a prey or following a free fall; it also allows spiderlings to maintain contact with the parental web. The dragline material is produced by a pair of major ampullate glands, while the material of attachment discs is secreted by piriform glands (Kovoor, 1987).

The presence of adhesive scopular setae, including claw tufts in araneomorphs and their probable function in the wandering species of several families, is well documented by a number of studies (Miller, Miller, and Brady, 1988; Wolff and Gorb, 2012; Wolff, Nentwig, and Gorb, 2013; Wolff and Gorb, 2015; Labarque et al., 2017). Based on his observations of wolf spiders (Lycosidae), Rovner (1978) concluded that the presence of scopular adhesive setae is one of the most important morpho- logical adaptations for prey capture seen in wandering spiders.

One of the prominent features of spiders of the infraorder Mygalomorphae (3,057 species) (World Spider Catalog, 2019), is the tendency towards a reduced number of spinnerets, leading to a limited diversity of spinning glands, spigots and produced silk. In all mygalomorphs, the anterior median spinnerets are completely extinct and a great number of these spiders also have reduced or non-functional ALSs.

Mygalomorphae do not possess the ability to form the above-mentioned lifelines and are also not capable of attaching their fibres to the substratum by attachment discs. Theraphosidae (147 genera and 1,000 species) (World Spider Catalog, 2019), display a spinning apparatus made up of only two pairs of spinnerets, located at the end of the ventral side of the opisthosoma. The secreted silk, which hardens when exposed to air, is in these spiders processed by the movements of the opisthosoma and the activity of long, limb-like posterior lateral spinnerets (Hajer, Karschová, and Řeháková, 2016).

Theraphosidae employ different adaptative mechanisms in order to make up for their inability to produce lifelines, so that they can move safely on rough or smooth, more or less vertically-oriented substrata. Tarantulas fleeing danger on smooth glass walls press their spinnerets to the opisthosoma in such a way that they do not come into contact with the wall at all. In this situation, no silk is emitted from the spinnerets. The main preventative mechanism protecting these, often quite large spiders, from falling into open space is represented by multibranched adhesive claw tuft setae. This multibranched hairy attachment system in the form in which it is developed in theraphosids shows a higher reliability of contact on various surface profiles and increased tolerance to individual contact defects (Federle, 2006).

The results of our observations prove that under certain circumstances tarantulas are capable of employing specialized tarsal setae to produce both fibrous material and fluid secretion which after drying does not exhibit a fibrous appearance. This material remains attached to the substratum on which the spiders move and also to the adhesive claw tufts forming setae. This phenomenon may be observed especially during fast movement of irritated specimens outside of their silk, tube-like shelter, or when these spiders move on the smooth surface of perpendicular glass walls, not previously covered by a layer of silk. SEM studies of the fibrous structures left on the glass walls and on the surface of the claw tuft setae confirmed the presence of two types of fibrous material: the fragments of hollow fibres forming the shaft and its lateral branches (1) and the already mentioned contracted nanofibrils, the tufts of which were accumulated on the ends of the tubular fibres (2). Fibres of the same (or at least similar) ultrastructure to the structure of silk 
fibres produced by spinnerets and spinneret-associated silk glands are, however, not produced by the activity of feet and claw tuft setae.

The presence of glands which could supply the secretion to adhesive setae, including claw tufts, has not yet been confirmed by anyone. Setae displaying morphology similar to the morphology of spigots cannot be considered to be true spigots, that is, structures through which silk is emitted, unless there is a known source (secretory epithelium) which could supply such a secretion. One example of that is "ribbed hairs", which some authors (Rind, Birkett, Duncan, and Ranken, 2011) consider to represent setae functioning in the same way as spigots. However, in this particular case it has been proven that "ribbed hairs" function as chemoreceptors (Foelix, Rast, and Peattie, 2012). Ribbed hairs are of special interest given their extraordinary length, due to which they rise above the surrounding claw tuft setae and are the first to come into contact with any substratum, before any of the adhesive setae which surround them. They are always seen as protruding above the bundles of adhesive setae, the distal parts of which are after climbing glued together with the solidified amorphous secretion.

However, what is deserving of special attention for the purposes of future research into secretion activity are the bundles of parallelly-oriented, hollow fibres forming the shaft of adhesive setae and their lateral branches, which are the probable source of the secretion which dries in contact with air and therefore probably represents an example of the secretion-producing system via surficial pathway. In this context it is important to bring to mind the concept of "glandular hairs" first described by Glatz $(1972,1973)$, based on their detailed study of the spinning apparatus of purse-web spiders of the genus Atypus Laterille, 1804 (Atypidae, Mygalomorphae). These setae are characterized by a widened basal part of the shafts and a long, gradually thinning terminal part, the thin ends of which are broken off so that the secretion contained within may be released. The function and chemical composition of this secretion has never been established. We believe it probable that in the case of tarantulas there is a release of fluid emitted by the tubular fibres forming the stalk of the claw tuft setae. It is the manner of the motion of the spider and the manipulation with the solidifying secretion which then determines the final filamentous or amorphous structure of the solidified materials.

The findings in Theraphosidae, similarly to other Mygalomorphae and many other spiders, suggest fluid as well as filamentous secretion being employed in order to enhance adhesion (Peattie, Dirks, Henriques, and Federle, 2011; Rind, Birkett, Duncan, and Ranken, 2011). In the case of the tarantulas studied in our work, the secretion produced by the feet of irritated spiders glued the groups of claw tuft setae together. Howev- er, the same secretion at the same time also covers the substratum-facing side of the distal lamellar parts and covers over their microtrichia, which then can no longer carry out their function of adhesive hairs. If the mass of adhesive fluid grants the disturbed tarantula an advantage when moving on a smooth surface, then it is an advantage distinctly short-lived. Tarantulas fleeing from danger are capable of moving on smooth, perpendicular walls for a couple of minutes only. Theoretical and experimental studies proved that the hairy design also helps to achieve self-cleaning properties, controllable detachment and increased adhesion (Federle, 2006). When assessing this phenomenon, it is necessary to take into consideration that arboreal tarantulas are not vagrant, or wandering spiders in the true sense of the word. Similarly to the builders of aerial webs of the infraorder Araneomorphae, they spend most of their life moving on a silk self-made substratum, which is represented by the walls of their silk, usually tube-like shelter or the surface of the surrounding objects which they themselves cover (that is pre-adapt) with a layer of silk.

\section{Acknowledgements}

This study was supported by the Grant Agency of J. E. Purkinje University in Ústí nad Labem, Czech Republic. The authors gratefully acknowledge the suggestions from the reviewers and the editor, which helped in improving the manuscript.

\section{References}

Arzt, E., Gorb, S., and Spolenak, R. 2003. From micro to nano contacts in biological attachment devices. Proceedings of the National Academy of Sciences 100(19):10603-10606. https://doi.org/10.1073/pnas.1534701100

Bond, J. E. 1994. Seta-spigot homology and silk production in 1st instar Antrodiaetus-unicolor spiderlings (Araneae, Antrodiaetidae). Journal of Arachnology 22(1):19-22.

Craig, C. L. 1997. Evolution of arthropod silks. Annual Review of Entomology 42:231-267. https://doi.org/10.1146/annurev.ento.42.1.231

Charpentier, P. 1992. Heterscodra maculata. British Tarantula Society Journal 8(2):11-19.

Dawydoff, C. 1949. Développement embryonnaire des arachnides.; 320-369 in: Traité de Zoologie, Anatomie, Systematique, Biologie, edited by Grassé, P. P. Paris: Masson.

Dunlop, J.A. 1995. Movements of scopulate claw tufts at the tarsus tip of a tarantula spider. Netherlands Journal of Zoology 45(3-4):513-520. https://doi. org/10.1163/156854295X00447

Eberhard, W. G. 2010. Possible functional significance of spigot placement on the spinnerets of spiders. Journal of Arachnology 38(3):407-414. https://doi.org/10.1636/ b09-97.1

Federle, W. 2006. Why are so many adhesive pads hairy? Journal of Experimental Biology 209(14):2611-2621. https:// doi.org/10.1242/jeb.02323

Ferretti, N., Pompozzi, G., Copperi, S., Wehitt, A., Galindez, E., Gonzalez, A., and Perez-Miles, F. 2017. A comparative morphological study of the epiandrous apparatus in mygalomorph spiders (Araneae, Mygalo- 
morphae). Micron 93:9-19. https://doi.org/10.1016/j. micron.2016.11.005

Foelix, R. 2011. Biology of Spiders. 3 ed. New York: Oxford University Press.

Foelix, R., Erb, B., and Michalik, P. 2010. Scopulate hairs in male Liphistius spiders: probable contact chemoreceptors. Journal of Arachnology 38(3):599-603. https://doi. org/10.1636/b10-42.1

Foelix, R., Erb, B., and Rast, B. 2013. Alleged silk spigots on tarantula feet: Electron microscopy reveals sensory innervation, no silk. Arthropod Structure \& Development 42(3):209-217. https://doi.org/10.1016/j. asd.2013.02.005

Foelix, R. F. and Chu-Wang, I. W. 1975. The structure of scopula hairs in spiders. Paper read at the $6^{\text {th }}$ International Congress of Arachnology at Amsterdam.

Foelix, R. F., Rast, B., and Peattie, A. M. 2012. Silk secretion from tarantula feet revisited: alleged spigots are probably chemoreceptors. Journal of Experimental Biology 215(7):1084-1089. https://doi.org/10.1242/jeb.066811

Garb, J. 2013. Spider silk. An ancient biomaterial for 21st century research.; 252-281 in: Spider Research in the 21st Century: trends \&, perspectives, edited by Penney, D.: Siri Scientific Press.

Glatz, L. 1972. Der Spinnapparat haplogyner Spinnen (Arachnida, Araneae). Zeitschrift für Morphologie der Tiere 72:126. https://doi.org/10.1007/BF00281752

Glatz, L. 1973. Der Spinnapparat der Orthognatha (Arachnidae, Araneae). Zeitschrift für Morphologie der Tiere 75:150. https://doi.org/10.1007/BF00723667

Gorb, S. N., Niederegger, S., Hayashi, C. Y., Summers, A. P., Voetsch, W., and Walther, P. 2006. Silk-like secretion from tarantula feet. Nature 443(7110):407-407. https:// doi.org/10.1038/443407a

Hajer, J., Karschová, S., and Řeháková, D. 2016. Silks and silkproducing organs of Neotropical tarantula Avicularia metallica (Araneae, Mygalomorphae, Theraphosidae). Ecologica Montenegrina 7:313-327.

Haupt, J. 2003. The Mesothelaea - monograph of an exception group of spiders (Araneae: Mesothelae). Morphology, behaviour, ecology, taxonomy, distribution and phylogeny. Zoologica 154:1-102.

Haupt, J. and Kovoor, J. 1993. Silk-gland system and silk production in Mesothelae (Araneae). Annales Des Sciences Naturelles-Zoologie Et Biologie Animale 14(2):35-48.

Hilbrant, M. and Damen, W. G. M. 2015. The embryonic origin of the ampullate silk glands of the spider Cupiennius salei. Arthropod Structure \& Development 44(3):280-288. https://doi.org/10.1016/j.asd.2015.04.001

Jocqué, R. and Dippenaar-Schoeman, A. S. 2006. Spider Families of the World. Koninklijk Museum voor Midden-Afrika.

Kautzch, G. 1910. Über die Entwicklung von Agelena labyrinthica Clerk. Zoologische Jahrbücher. Abteilung für Anatomie und Ontogenie der Tiere 28:30-36.

Kovoor, J. 1987. Comparative structure and histochemistry of silk-producing organs in Arachnids; 160-186 in: Ecophysiology of Spiders, edited by Nentwig, W. Berlin, Heidelberg: Springer Berlin Heidelberg. https://doi. org/10.1007/978-3-642-71552-5_12

Kropf, C. 2013. Hydraulic system of locomotion; 43-56 in: Spider Ecophysiology, edited by Nentwig, W. Berlin, Heidelberg: Springer Berlin Heidelberg. https://doi. org/10.1007/978-3-642-33989-9_4

Labarque, F. M., Wolff, J. O., Michalik, P., Griswold, C. E., and Ramirez, M.J. 2017. The evolution and function of spider feet (Araneae: Arachnida): multiple acquisitions of distal articulations. Zoological Journal of the Linnean Soci- ety 181(2):308-341. https://doi.org/10.1093/zoolinnean/ zlw030

Lopez, A. and Emerit, M. 1988. New data on the epigastric apparatus of male of spiders. Bulletin of the British Arachnological Society 7(7):220-224.

Marples, B. J. 1967. The spinnerets and epiandrous glands of spiders. Zoological Journal of the Linnean Society 46(310):209222. https://doi.org/10.1111/j.1096-3642.1967.tb00504.x

Miller, G. L., P. R., M., and A. R., B. 1988. Adhesive hairs in lycosid spiders of various life styles, including the occurence of claw tufts in Lycosa hentzi Banks. Bulletin of the British Arachnological Society 7(7):213-216.

Neretin, N.Y. 2016. The Morphology and ultrastructure of "Amphipod silk" glands in Ampithoe rubricata (Crustacea, Amphipoda, Ampithoidae). Biology Bulletin 43(7):628642. https://doi.org/10.1134/s106235901607013x

Niederegger, S. 2013. Functional aspects of spider scopulae; 57-66 in: Spider Ecophysiology, edited by Nentwig, W. Berlin, Heidelberg: Springer Berlin Heidelberg. https:// doi.org/10.1007/978-3-642-33989-9 5

Niewiarowski, P. H., Stark, A. Y., and Dhinojwala, A. 2016. Sticking to the story: outstanding challenges in geckoinspired adhesives. Journal of Experimental Biology 219(7):912-919. https://doi.org/10.1242/jeb.080085

Osaki, S. 1996. Spider silk as mechanical lifeline. Nature 384(6608):419-419. https://doi.org/10.1038/384419a0

Peattie, A. M., Dirks, J. H., Henriques, S., and Federle, W. 2011. Arachnids secrete a fluid over their adhesive pads. Plos One 6(5). https://doi.org/10.1371/journal.pone.0020485

Pechmann, M., Khadjeh, S., Sprenger, F., and Prpic, N. M. 2010. Patterning mechanisms and morphological diversity of spider appendages and their importance for spider evolution. Arthropod Structure \& Development 39(6):453-467. https://doi.org/10.1016/j.asd.2010.07.007

Perez-Miles, F., Perafan, C., and Santamaria, L. 2015. Tarantulas (Araneae: Theraphosidae) use different adhesive pads complementarily during climbing on smooth surfaces: experimental approach in eight arboreal and burrower species. Biology Open 4(12):1643-1648. https:// doi.org/10.1242/bio.013144

Perez-Miles, F., Panzera, A., Ortiz-Villatoro, D., and Perdomo, C. 2009. Silk production from tarantula feet questioned. Nature 461(7267):E9. https://doi.org/10.1038/ nature08404

Rind, F. C., Birkett, C. L., Duncan, B.-J.A., and Ranken, A.J. 2011. Tarantulas cling to smooth vertical surfaces by secreting silk from their feet. Journal of Experimental Biology 214(11):1874-1879. https://doi.org/10.1242/jeb.055657

Rovner, J. S. 1978. Adhesive hairs in spiders: behavioral functions and hydraulically mediated movement. Symposia of the Zoological Society of London 42:99-108.

Seyfarth, E. A. and Pfluger, H.J. 1984. Proprioreceptor distribution and control of muscle-reflex in the tibia of spider legs. Journal of Neurobiology 15(5):365-374. https://doi. org/10.1002/neu.480150506

Shultz, J.W. 1987. The origin of the spinning apparatus in spiders. Biological Reviews of the Cambridge Philosophical Society 62(2):89-113. https://doi.org/10.1111/j.1469185X.1987.tb01263.x

Sutherland, T. D., Young, J. H., Weisman, S., Hayashi, C. Y., and Merritt, D. J. 2010. Insect silk: one name, many materials. Annual Review of Entomology 55(1):171-188. https://doi. org/10.1146/annurev-ento-112408-085401

Tirrell, D.A. 1996. Putting a new spin on spider silk. Science 271(5245):39-40. https://doi.org/10.1126/science.271.5245.39

Whitehead, W. F. and Rempel, J. G. 1959. A study of the musculature of the black window spider, Latrodectus mac- 
tans (Fabr.). Canadian Journal of Zoology 37(6):831-870. https://doi.org/10.1139/z59-084

Wolff, J. O. and Gorb, S. N. 2012. Comparative morphology of pretarsal scopulae in eleven spider families. Arthropod Structure \& Development 41(5):419-433. https://doi. org/10.1016/j.asd.2012.04.004

Wolff, J. O. and Gorb, S. N. 2015. Adhesive foot pads: an adaptation to climbing? An ecological survey in hunting spiders. Zoology 118(1):1-7. https://doi.org/10.1016/j. zool.2014.04.006
Wolff, J. O., Nentwig, W., and Gorb, S. N. 2013. The great silk alternative: multiple co-evolution of web loss and sticky hairs in spiders. Plos One 8(5). https://doi.org/10.1371/ journal.pone.0062682

World Spider Catalog.Version 20.0 2019. Natural History Museum Bern 2019 [cited 15. 6. 2019]. Available from http:// wsc.nmbe.ch

Yoshicura, M. 1955. Embryological studies on the liphistiid spider Heptathel kimurai. Kumamoto Journal of Science Series B 2/3:41-48. 